\title{
ENTRE LITERATURA Y FOTOGRAFÍA: EL MITO DE MEDUSA EN ÁLBUM DE FAMILIA DE ROSARIO CASTELLANOS (LA CONDICIÓN FEMENINA Y LA PROBLEMÁTICA DEL ESPEJO)
}

Between Literature and Photography: The Myth of Medusa in Rosario Castellanos's Álbum de Familia (the Female Condition and the Mirror Problem)

MARIA ALEJANDRA TORRES

Universidad de Buenos Aires / CONICET (Argentina)

alemariatorres@gmail.com

ORCID: https://orcid.org/0000-0001-5108-5938

Resumen

En este artículo consideramos que Rosario Castellanos toma el mito de Medusa para visibilizar el modo en que las mujeres escritoras han sido "fijadas" en la cultura mexicana como si fueran una fotografía en un estereotipo monstruoso y, a la vez, recurre al mito para constituir una alegoría de figuras reflexivas en las cuales las mujeres pueden inscribirse de otra manera. Leemos esta operación en el cuento "Álbum de familia" (1971), relato intermedial que, como una fotografía, nos muestra a personajes femeninos que buscan otra manera de estar en el mundo y de representarse a sí mismas, pero para ello tienen que confrontarse con el discurso masculino y con una serie de oposiciones binarias de la cultura occidental que las han determinado y sujetado a un estereotipo que las encorseta. 


\section{Palabras clave}

Rosario Castellanos, Álbum de familia, el mito de Medusa, intermedialidad

\section{Abstract}

In the present article, we propose that Rosario Castellanos uses the Myth of Medusa to visibilize the way in which women writers in Mexican culture has been "fixed" - the same way a photograph is fixed - as some monstrous stereotype; at the same time, this Myth is used to construct an allegory of reflexive figures where women can be otherwise inscribed. "Album de familia" (1971) may be read in the story, a story intermedial that, like photographs, presents female characters looking for another way of being and selfrepresenting, thus confronting stereotypes and male discourses, as well as a set of binary oppositions of Western culture that limits and restrains them to a sole way of being and expressing themselves

\section{Keywords}

Rosario Castellanos, Álbum de familia, Myth of Medusa, Intermediality

\section{Un álbum familiar: la escritura de mujeres}

En América Latina, una genealogía de escritoras que se remonta a la mexicana Sor Juana Inés de la Cruz ha producido textos en relación con el mundo de las mujeres y el lugar que ocupan en la sociedad, los modos de adquirir conocimiento y de autoafirmarse y también las posibilidades que ofrecen las imágenes técnicas en estos procesos. En el caso de la monja, recordamos que en su famoso El Sueño, se refiere al espectáculo de la linterna mágica como metáfora del conocimiento en el argumento general del complejo poema. ${ }^{1}$ A mediados del siglo XX, una generación de escritoras mexicanas que comparten el mismo contexto histórico-social y similares preocupaciones sobre cuestiones literarias y estéticas visibilizan en sus textos esas problemáticas y plantean nuevos modos de ver el mundo y la cultura que las rodea. ${ }^{2}$

En el caso de la escritora Rosario Castellanos es evidente su preocupación (como puede leerse en la obra de sor Juana Inés de la Cruz) por la condición femenina y por el lugar de las mujeres en la sociedad, así como por las posibilidades de autoafirmación, autorrepresentación y conocimiento. Explícitamente, en el ensayo Mujer que sabe latín (1973) Castellanos hace referencia a Sor Juana y afirma que su camino es un camino de conocimiento y que ella supo aprovechar las reprimendas recibidas al escribir un texto a su

\footnotetext{
${ }^{1}$ La linterna mágica era un primitivo proyector luminoso de imágenes, un aparato óptico cuya invención se atribuye al jesuita alemán Athanasius Kircher, los versos del Primero sueño demuestran que Sor Juana conocía bien el espectáculo de la linterna mágica, las figuras fingidas creadas por el arte de la luz y la sombra. Ver "El sueño", en Sor Juana Inés de la Cruz (2004), Obras completas, Tomo I. pp. 335-359.

2 Nos referimos a Rosario Castellanos, Inés Arredondo, Amparo Dávila, Guadalupe Dueñas, Julieta Campos, Josefina Vincens, María Lombardo de Caso, Luisa Josefina Hernández, entre otras.
} 
favor, en defensa de sus convicciones. Este planteamiento se inscribe en las reflexiones sobre las posibilidades que tienen las escritoras de construir su imagen propia:

Y cuando el cristal de las aguas se enturbia y los ojos del hombre enamorado se cierran y las letanías de los poetas se agotan y la lira enmudece, aún queda un recurso: construir la propia imagen, hacer un testamento a la posteridad (para darle lo que se tuvo pero ante todo para hacer constar aquello de lo que se careció), evocar su vida. (2017: 33-36; las cursivas son mías) ${ }^{3}$

En la escritura de este ensayo se materializa la búsqueda de Castellanos por hallar un lenguaje propio para dar forma a sus ideas y por esa razón elige un modo de "enunciación transpersonal y no uno íntimo; inscribe sus textos en ámbitos más amplios de sentido y convoca a una gran cantidad de voces para fortalecer la suya" (Castro Recalde, 2010: 175). En este sentido, destacamos que en su producción indaga en las posibilidades del lenguaje para fortalecer su propia voz y su imagen, ejes fundamentales de su escritura. Rosario Castellanos ha incursionado en una variedad de lenguajes y formas de expresión, por lo cual planteamos que parte de estas búsquedas encuentra en el cuento "Álbum de familia" un lugar privilegiado de experimentación: a partir de la representación de una mujer escritora, Castellanos reflexiona sobre las posibilidades de las imágenes técnicas para plantear la problemática de la identificación, de la búsqueda de identidad de las escritoras y, de modo más amplio, del lugar de las mujeres en la cultura.

En este artículo proponemos una lectura intermedial del cuento a través del mito de Medusa, que operaría como un "obturador" cuyo "revelado" fotográfico captura una imagen fantasmagórica indescernible, la imagen de una escritora en México del siglo XX en tanto rehén del discurso masculino. Al mismo tiempo, afirmamos que este cuento se coloca entre la literatura y la fototeoría y que, a partir de las metáforas de la fotografía, Castellanos se adentra en la problemática de la autorrepresentación y de la sexualidad.

Nuestro marco de análisis toma como eje la perspectiva crítica intermedial, entendida no solo como una mixtura de medios y/o lenguajes que privilegia los modos de ser entre ellos una vez que entran en contacto con obras particulares sino también como referencia entre medios, es decir, un solo medio que en su discurso o forma se refiere a otro (Paech, 1998; Rajewsky, 2002; Wolf, 2011). A propósito de este modo de lectura, señalamos que el cuento "Álbum de familia" remite a un libro en blanco para escribir, pero también un "álbum" es un libro donde se coleccionan cosas: grabados, figuras, fotografías. Por ello, el texto se presenta como un continuum fotográfico que es, por ende, inter-medial en tanto exhibe una huella de otro medio en la concepción de este y que se resume en el título.

Asimismo, examinamos la teoría de la fotografía y nos enfocamos en "lo fotográfico", tal como lo define Philippe Dubois en tanto categoría epistémica: "una verdadera categoría de pensamiento, absolutamente singular y que introduce a una relación específica con los signos, con el tiempo, con el espacio, con lo real, con el ser y con el hacer" (Dubois, 1986: 54). A partir de esta definición se puede considerar "lo fotográfico" como un campo de reflexión abierto a las múltiples relaciones entre disciplinas y entre medios. Por su parte, es productivo considerar también a la crítica Rosalind Krauss (2002), quien define "lo fotográfico" como objeto teórico que tiene en cuenta el carácter indicial de la fotografía en tanto inscripción, escritura y, a la vez, indaga sobre el medio mismo, es decir, sobre el aparato y las relaciones que suscita en el mundo del arte. ${ }^{4}$ Como consecuencia de estas lecturas, señalamos que el cuento que lleva el título del libro remite a la fotografía en tanto dispositivo que fija una imagen y

\footnotetext{
${ }^{3}$ En el capítulo "La mujer ante el espejo: cinco autobiografías", Castellanos afirma que el modo de evocación cambia con las épocas y por eso analiza la construcción de la propia imagen no solo en Sor Juana sino también en Santa Teresa, Virginia Woolf, Simone de Beauvoir y Elena Croce.

${ }^{4}$ Sobre la cuestión de la indicialidad de la fotografía seguimos la lectura de Dubois, quien en El acto fotográfico considera con exhaustividad las concepciones de la fotografía en el recorrido que va de la verosimilitud al índex y analiza los tres discursos: el de la fotografía como espejo de lo real, la fotografía como transformación con lo real y la fotografía como huella de una realidad, es decir, como inscripción o escritura.
} 
pone en escena lo que Dubois denomina "acto fotográfico", es decir, la imagen acto que se constituye en el momento del corte temporal y espacial.

En las reflexiones que ocasiona el cuento de Rosario Castellanos pareciera que la escritora "se adelantara" a la categoría de "lo fotográfico" para examinar el problema del origen de la representación y por eso se remonta a un mito que da primacía a la visión: el mito de Medusa. Con el relato de este mito y tal como lo afirma Dubois, "permanecemos en el campo de la indicialidad, del autorretrato y de la paradoja" (Dubois, 1986: 127) porque a la imagen proyectada le va a suceder la imagen reflejada en el espejo.

En relación con la problemática de la representación y la sexualidad recordamos que el cuento "Álbum de familia" ocupa el capítulo nueve del libro Rito de iniciación que Castellanos se negó a publicar en vida y en el que el personaje central, Cecilia Rojas, es un alter ego de la autora (Bustamante Bermúdez, 2007; Valenzuela 2010). La escritora Luisa Valenzuela afirma que en esa novela asistimos al camino de Cecilia Rojas, quien "recorrerá por su cuenta el duro camino de abrirse a una vocación. Y esa vocación es la escritura" (Valenzuela, 2010: 365). Agregamos que la búsqueda del personaje de Cecilia Rojas/Rosario Castellanos puede resumirse en atravesar un rostro para llegar a la escritura.

$\mathrm{Al}$ definir su propia escritura, Helene Cixous ha señalado que en el rostro están inscriptos y también guardados los misterios y que siempre el deseo de escribir tiene que encontrar en el rostro propio la propia morada (2006). Por lo expuesto, en este artículo intentamos mostrar que en "Álbum de familia", a través de la búsqueda del personaje Cecilia y la mirada sobre una poeta consagrada que habita el Olimpo, Matilde Casanova, se tematiza la búsqueda de una imagen propia, de un rostro, a la vez que se reflexiona sobre la mirada, sobre las posibilidades de la técnica, sobre la constitución del sujeto y las posibilidades de autoafirmación.

Dos jóvenes, Cecilia y su amiga Susana, quieren entrevistar a Matilde Casanova y por eso van a visitarla. A partir de la interacción y diálogo entre las jóvenes, la poeta y sus amigas escritoras Josefa, Victoria, Elvira y Amita, se reflexiona sobre el lugar de las mujeres en la cultura y, especialmente, de las escritoras. Casanova, una especie de Medusa, muestra a las jóvenes un modo posible de ser escritora, aceptada y premiada:

Ni Cecilia ni su compañera habían tenido acceso hasta el Olimpo en el que habitaba Matilde agobiada por compromisos oficiales, asediada por personajes de la política, de la cultura y hasta de las finanzas, acechada por fotógrafos, perseguida por cazadores de autógrafos, rodeada siempre de curiosos, tanto profesionales como aficionados. $(1971: 10)^{5}$

Las jóvenes Cecilia y su amiga Susana ven en Matilde Casanova un espejo donde mirarse, sin embargo, lo rechazan para buscar nuevos lenguajes y formas de expresión.

El relato exhibe la problemática del espejo y por medio de la reflexión sobre el dispositivo fotográfico muestra los reflejos y las imágenes desviadas. En el texto, todas las protagonistas miran su situación en el mundo, se miran a sí mismas, miran los espejos donde reflejarse, miran el mundo masculino, reciben la mirada de ellos y también miran la historia de las mujeres para posicionarse.

\section{La búsqueda de un rostro y el mito de Medusa}

En la cultura mexicana de mediados de siglo XX la pregunta por la noción de identidad es una cuestión ineludible para los escritores de la época. El tema de la mexicanidad atraviesa el pensamiento de

\footnotetext{
${ }^{5}$ Para Gerardo Bustamante Bermúdez (2007), el personaje de Matilde Casanova está tomado de la vida de Gabriela Mistral.
} 
Samuel Ramos, en los años treinta, hasta Uranga en los cincuenta seguido por Leopoldo Zea, Edmundo O’ Gorman, Agustín Yáñez, Adolfo Menéndez Samara, José Iturriaga, entre otros. En este sentido, El laberinto de la soledad de Octavio Paz, publicado en 1950, sintetizó esas búsquedas (Sefchovich, 1987: 111). En el texto de Paz se afirma que la mujer tiene una inferioridad constitucional y esta radica, específicamente, en su sexo. Las escritoras mexicanas han tenido que forjarse un lugar en la tradición que las sitúa como las "hijas de la Malinche". La escritora Margo Glantz reflexiona en torno a ello:

Si todos somos los hijos de la Malinche, hasta las mujeres, ¿cómo pueden ellas (podemos nosotras) compartir o discernir su (nuestra) porción de culpa y hasta de cuerpo? Llevar el nombre genérico de la Chingada como mujeres es mil veces peor, es carecer de rostro, o tener uno impuesto: para verse hay que descubrir la verdadera imagen, cruzar el espejo, lavar la "mancha", Rosario Castellanos sintetiza en un fragmento de un poema esta idea: "No es posible vivir / con este rostro / que es el mío verdadero I y que aún no conozco". Si el hombre mexicano es un no ser, ¿qué es entonces la mujer mexicana, o simplemente, en este caso, la mujer? ¿Cómo se enfrenta ella a esta esencia negativa? (Glantz, 1994: 182; las cursivas son mías)

En cursiva destacamos que, en el caso de la escritura de Rosario Castellanos, y especialmente en este relato, en las mujeres que buscan su rostro esa búsqueda se hace identidad colectiva y se extiende a otras mujeres. Glantz analiza, especialmente, cómo Castellanos en la novela Balún Canán publicada en 1957 convergen "dos personajes sin rostro de la historia mexicana, los desterrados de la Historia universal: los indios y las mijeres" (183; las cursivas son mías). En dicho territorio se insertaría la Malinche como un lugar, el de la infancia.

Para bucear sobre las posibilidades de encontrar una imagen propia, un rostro, la escritora, al igual que Octavio Paz, retoma un mito, el de Medusa, y a través de ese mito puede constituir una alegoría de figuras reflexivas, por ejemplo, psicoanalíticas, porque la propia petrificación del gesto petrificador ocurre por medio de un espejo. Los hombres, entonces, pueden "chingar" a la Malinche por sus recursos de masculinidad, mientras que, para vencer a Medusa, Perseo tiene que desviar los propios poderes de la mujer, es decir, su propio gesto fatal. Dadas las reflexiones de Paz y del imaginario sociológico de México de esas décadas, se torna complejo considerar a la "Malinche" como una figura de reflexividad porque ha sido pensada desde una constelación de poder bajo la dialéctica de "Herr-Knecht" retomada por Octavio Paz de Hegel, es decir, una figura de contraste actividad versus pasividad.

Tal como ha destacado la crítica, Álbum de familia significa adentrarse en la situación conflictiva de la mujer en su contexto social (Mateu Serra, 1996), especialmente en el cuento homónimo, la figura de Medusa es "encarnada" en la sociedad de su tiempo, por lo tanto, el mito está contextualizado e historizado. ${ }^{6}$ En el relato, Castellanos visibiliza en la ficción a una mujer que escribe "poetisa mexicana recientemente agraciada con el premio de las Naciones" (Mateu Serra, 1996: 66), que es calificada en el texto como un "mascarón de proa" (138; las cursivas son mías), como un monstruo ambiguo, masculino y femenino a la vez, a la que la tierra firme rechaza por salirse de la norma, de lo establecido y por eso se la debe divinizar.

Destacamos que la problemática del "mascarón o máscara" se remonta a la antigüedad clásica dado que en Grecia las figuras del Otro, la forma en como los griegos representaban a sus dioses, los vínculos y las relaciones simbólicas le permitían al creyente asociar a tal o cual divinidad con el ídolo cuya misión era evocarla, hacerla presente ante él. En ese marco, Jean-Pierre Vernant (1985) descubre el problema de los dioses griegos con máscaras, aquellos cuyo símbolo era una máscara o cuyo culto comportaba el uso de máscaras. Por eso, se detiene en tres figuras: Gorgo (la gorgona Medusa), Dioniso

\footnotetext{
${ }^{6}$ Para Mateu Serra, Álbum de familia continúa la veta del grupo de ensayos de la autora a partir de los años sesenta, que han sido calificados de feministas por la mayoría de los críticos, y que "se han centrado, sobre todo, en el intento de desmitificar la imagen de la mujer por medio del tono humorístico” (Mateu Serra, 1996: 77).
} 
y Artemisa. Para Vernant cada una de estas figuras guarda relación con lo que él denominará la alteridad, es decir, refleja la experiencia de los griegos con el Otro:

la máscara monstruosa de Gorgo expresa la alteridad extrema, el horror pavoroso de lo que es absolutamente otro, lo indecible, lo impensable, el puro caos: para el hombre significa enfrentar la muerte, esa muerte que el ojo de Gorgo dispensa a aquellos que se cruzan con su mirada, que transforma todo cuanto vive, se mueve y ve la luz del sol en piedra inmóvil, congelada, ciega y sumida en las tinieblas. (Vernant, 1985: 16)

La máscara de la Gorgona manifiesta lo que es absolutamente Otro y, por eso, quien se cruza con ella se enfrenta a la muerte, ya que el ojo de Gorgo petrifica. Para el teórico Philippe Dubois en esas pequeñas muertes "sólo se trata de Fotografía" (Dubois, 1990: 133; las cursivas son mías). Es decir, el horror y el temor que suscita la cabeza de Medusa por las fijaciones y petrificaciones que produce se convierte en metáfora de la Fotografía.

En este punto, en nuestra lectura nos preguntamos ¿por qué Castellanos pone en escena el acto fotográfico en tanto acto de medusación? y proponemos que la escritora usa el mito de la Medusa para narrar el instante en que se fija una mirada y se petrifica un momento en que la mujer está "deviniendo imagen de sí misma", en la cultura de México. Por esta razón, la escritora al utilizar la "cabeza de Medusa" se remonta a la representación clásica de la fantasía de castración que retorna en los imaginarios y en los discursos falocéntricos y en los que se imbrican la toma de posición de la mujer y su escritura.

En este sentido, la noción de "lo fotográfico" que esbozamos se complejiza con una predicación leída en el texto, "el mascarón", que trae a la lectura crítica la noción de otredad y de una petrificación que lleva a la muerte y abre a otra cuestión donde se mixtura la representación clásica con la lectura hecha por Freud sobre el complejo de castración. Para la teoría freudiana, el descubrimiento de la diferencia anatómica es traumático, de allí que se establezcan varias defensas contra ese conocimiento terrible, esa expulsión de la unidad paradisíaca con la madre. La crítica de arte Griselda Pollock afirma que se puede negar el conocimiento, es decir, lo sabemos pero actuamos como si no lo supiéramos, y vivimos con el constante peligro de ser confrontados con ese conocimiento amenazante (Pollock, 2013: 247). Tal como se narra en el mito, con la melena poblada de serpientes como compensación fálica, Medusa convertirá en piedra a aquel que la mire de manera directa. Para Pollock el hecho de que pueda vérsela sin riesgos desde un espejo es "una imagen muy significativa en relación con la función de la representación visual y el posicionamiento sexual" (Pollock, 248). En este sentido, la teórica francesa Hélène Cixous en La risa de la Medusa deconstruye este mito y parte de una premisa básica: el rechazo radical de la tradicional jerarquización del discurso (filosófico, literario, cultural) en oposiciones binarias, por considerarla una disposición reduccionista que somete siempre de forma violenta uno de los términos de la pareja. Producto de ese dualismo, a lo largo de la Historia, la Mujer ha sido asociada dentro de un esquema falogocéntrico a lo femenino/pasivo en oposición dialéctica con lo masculino/activo, que la ha convertido en mero objeto (Cixous, 2001). Para Inés Lantero, lo que Cixous denomina "la gran impostura masculina" es esta concepción tradicional del deseo masculino vinculada a la apropiación, a la destrucción del otro, de lo otro, de lo no-propio entendido como amenaza, o, en términos psicoanalíticos, como castración (Marcos Lantero, 2008: s/p).

Cixous realiza un minucioso ejercicio deconstructivista del discurso falogocéntrico tradicional con el fin de anunciar en su lugar un "pensamiento otro", en el que el papel de lo femenino y, sobre todo, de la escritura femenina ocupa un lugar privilegiado. En esta elaboración, invita a reflexionar y dar un paso a una acción que dé lugar a un pensamiento de la diferencia, una de cuyas bases es la economía libidinal femenina: "si existe algo propio de la mujer es su capacidad para des-apropiarse sin egoísmo" (Cixous, 2001: 48), es decir, no apropiadora como la masculina, sino "dadora”, no excluyente. De ahí que considere la bisexualidad femenina concebida como la inscripción del otro en el sí mismo, característica 
más difícil de hallar en el hombre, ya que la presión del sistema falocéntrico le exige "aspirar a la gloriosa monosexualidad fálica" (Cixous, 2001: 45).

Sostenemos que, en un mismo horizonte de sentido que Cixous (recordamos que las producciones son casi de los mismos años), Rosario Castellanos usa el mito de la Medusa para salir del esquema activo/pasivo, introducirnos en la problemática del espejo y para reflexionar sobre una nueva manera de inscripción. Recordamos que, como la mirada de esta figura monstruosa de la Gorgona tenía el poder de petrificar, de herir a quienes la miraban, en el mito de Medusa narrado por Ovidio, Perseo encargado de cortarle la cabeza para no enfrentarse con esa mirada poderosa se protege con su escudo de bronce pulido, gracias a lo cual le devuelve a Medusa su propia mirada mortal que rebota en el espejo que le tiende Perseo para alcanzarla a su vez. Si Perseo al cortarle la cabeza a la Medusa volvió su mirada hacia su escudo en donde veía reflejada la imagen del monstruo, la cabeza sin fuerzas de la medusa es como la sombra de un hombre o como "su reflejo en un espejo" (Dubois, 1986: 134). ${ }^{7}$ La figura de la Medusa es una mitología de la fotografía misma, su espejo y su fantasma.

Rosario Castellanos recurre al mito para narrar, literaturizar, hacer visible el lugar de la mujer en México en el momento en que ella misma está produciendo sus textos y, también, en la dificultad, hasta en la imposibilidad de fijar una huella. Esta problematización se lee en la construcción del personaje de la poeta Matilde Casanova. Así se describe en el texto al personaje de la poeta Matilde Casanova: "Avanzaba a ciegas, por el tránsito brusco de la oscuridad a la plena luz. Su estatura noble parecía encorvada... Su pelo, entrecano ya, largo y crespo, se derramaba en desorden sobre sus hombros, sobre su espalda, hasta hacerla semejante a una fatigada e inofensiva Medusa" (1971: 80). El detalle del pelo de Matilde, largo, crespo y esparcido sobre sus hombros da cuenta de una imagen medusesca y, además, se predica sobre el estado psicofísico: está fatigada y es inocua. La poetisa ya cansada, sin la potencia de sus comienzos, cumple su vocación y el éxito la corona, pero ella muy agobiada por compromisos varios y "acechada por los fotógrafos" no es feliz. La protagonista cumple órdenes ajenas a su voluntad dado que se ha embarcado en un exilio que no ha elegido para cumplir con los designios de su gobierno.

La que otrora fuera un animal monstruoso, Matilde Casanova, no puede reconocerse ni en las fotografías:

\begin{abstract}
Su rostro, cuyas facciones resultaban siempre borrosas en las fotografías (y esta indiscernibilidad era atribuida a la imperfección de los aparatos que las habían querido captar, a la falta de destreza o a la prisa de quienes manejaban estos aparatos, a la distancia de la que se transmitía la imagen), había acabado por obedecer a una representación tan tenazmente reproducida, desdibujando los rasgos hasta no dejar sino una superficie disponible, una especie de tierra de nadie, un sitio en el que les estaba prohibido entablar batalla a los antagonistas encarnizados, irreductibles que convivían en la persona de Matilde. (1971: 80/81; las cursivas son mías)
\end{abstract}

En esta larga cita, destacamos y sostenemos que un discurso mediatiza el rostro de la poeta. Se trata de un discurso masculino que no puede asirla ni representarla "en tanto mujer" que solamente consigue darle un lugar de una identidad fija, serial, de copia, de reproducción. En esas copias, donde el rostro se desdibuja, no hay lugar para las múltiples contradicciones, no hay lugar para las diferencias internas del sujeto. El rostro de la poeta premiada "que en ciertos años llegó a asumir un aspecto de parálisis, terminó por resolverse en el gesto hierático de los indios de quienes Matilde, ya desde antes, se

\footnotetext{
${ }^{7}$ Recordamos que en el mito clásico, antes de convertirse en un monstruo de horror y de espanto, Medusa era, según la leyenda, una mujer de belleza radiante y sus cabellos era lo que más atraía de su personalidad, y por eso es castigada por Atenea, la celosa, por haber seducido a Poseidón que la violó sobre el templo de Minerva, entonces, Medusa verá como su cabellera se transforma en un magma de serpientes y cualquiera que se acercara y cayera bajo la mirada de sus ojos seductores quedaría transformado en piedra.
} 
había proclamado la descendiente orgullosa" (80-81), indios y mujeres, entonces, asumen el gesto que le atribuye la "cultura masculina".

Esta imagen petrificada de la escritora en el Olimpo, paralizada, se resuelve en un gesto de aceptación de un rostro, y un nombre, aquel que pronunció el discurso masculino. El rostro de Matilde es "indiscernible" a una imagen fantasmagórica, y esto se atribuye a los fotógrafos y a los aparatos técnicos, a la distancia con que se transmitía la imagen. Esta separación temporal, esta distancia a la que se alude en el texto, se corresponde con el proceso técnico del revelado, con sus fases sucesivas obligatorias que van de la imagen latente a la imagen revelada y luego a la imagen fijada.

Sabemos por la teoría de la fotografía que, entre la latencia y la imagen revelada, en ese lapso de tiempo, en ese pasaje, pueden pasar muchas cosas. Mientras se espera el momento del revelado, de la Revelación, aparecen las preguntas técnicas de un fotógrafo: "habré hecho un buen encuadre, habré captado bien ese momento expresivo de un rostro" (Dubois, 1986: 88). Estas preguntas son las mismas que aparecen en el cuento "Álbum de familia". Es por eso que la prisa de un fotógrafo o la destreza para captar bien un rostro son dudas esenciales, que tienen que ver con la cuestión de la identidad.

En ese estado de imagen latente, en ese distanciamiento, se manifiesta la relación de la fotografía con la alucinación dado que hay un desface temporal entre el objeto y su imagen. El principio de distancia espaciotemporal propia del hecho fotográfico es el contrapunto del principio indicial de la proximidad física, del contacto, de la huella que marca un momento constitutivo en el proceso fotográfico. Por esta razón, para Dubois, en el desajuste de la representación, el sujeto se mueve "entre dos mundos que no coinciden, y compulsivamente se pierde en las apariencias, preso en el juego de los fantasmas, las ficciones, los espejismos, abismándose cada vez más, cavando su propia tumba" (Dubois, 1986: 89). La distancia fotográfica es el lugar donde vacilan todas las certezas.

Como hemos señalado, en el cuento la poeta Matilde se representa como un fantasma. Su aparición en la escena textual se convierte en espectáculo, en una visión casi espectral que solo puede ser contemplada. La joven estudiante de literatura, Cecilia, capta que esta imagen fantasmal "no dejaba de emanar cierta cualidad irreal, es decir, que obedecía a un orden diferente del que rige sobre los hechos" (1971: 84) a la vez que admite que esta imagen la fascina. La figura de Matilde, como en el mito la de Medusa, produce en quien la contempla fascinación, a la vez que rechazo. Las ex-alumnas de la poetisa, que la siguen, que la tienen en el Olimpo, como alguien fuera de la vida real, parecen querer otra cosa, no quieren una imagen fantasmagórica, quieren una imagen conformada, quieren certidumbre indexical, huella. La imagen que les devuelve Matilde es un engaño, un desface, una mascarada.

En relación con la construcción del mito del espejo, el texto también construye sus espejos. La poeta que escribe temas inofensivos, que es reproductora de discursos masculinos, antes fue quien dirigía un escuadrón de vírgenes fuertes/ poderosas que la seguían. En los discursos de las discípulas de la poeta hay reproches por haber acatado sin reparos las órdenes de la mujer a quienes admiraban en la juventud:

Yo he vivido con Matilde y no hay horror al que no la haya visto descender ni triunfo con el que no la hayan coronado. He visto a ese mascarón de proa, como dice Elvira, abrirse paso entre el oleaje embravecido y mantenerse a la deriva en alta mar porque la tierra firme la rechaza. No hay lugar para los monstruos. (1971: 133)

El diálogo entre las ex alumnas Josefa, Aminta, Victoria no tiene ambages y reafirma el lugar que la sociedad dominada por los hombres de la cultura han colocado a una escritora como Matilde Casanova:

La condujeron en andas al altar, la hartaron de ofrendas y la cubrieron con un capelo de vidrio para que su contemplación no resulte peligrosa para la multitu [...] y también para que se asfixie más pronto. 
Sabedores de la proximidad del fin, los grandes sacerdotes la ungen ya con los últimos óleos y los embalsamadores se preparan. (134; las cursivas son mías)

En nuestro subrayado apreciamos cómo se va intercalando el mito en las conversaciones sobre Matilde/Medusa, y en este enunciado se hace referencia a la mirada peligrosa. Mientras las exalumnas le recriminan a Victoria Benavidez, la secretaria, el no haberse alejado a tiempo de la poeta; esta afirma que no se alejó porque "no hallé ningún escudo que sirviera" (134; las cursivas son mías) en clara alusión al escudo de Perseo para protegerse de la mitológica figura de Medusa. La conversación gira en torno a las identificaciones posibles y a la necesidad de que en tanto mujeres puedan descubrir la "propia figura que nos corresponde" (137), la imagen propia. En el caso de Matilde se sabe que conoce la fuerza, el poder de las mujeres, pero por efecto discursivo, por ser narrada por los hombres, pierde fuerza, y se convierte en una imagen fantasmal que remite a un asedio que replica con los sentidos de la muerte.

El texto contrasta momentos de tiempo. Oscila entre la imagen fantasmal, una presencia-ausencia del personaje, y los momentos de potencia de la mujer escritora. Entre esas dos representaciones se van identificando las demás protagonistas. Así también se muestra la zona de la sexualidad homosexual y de la bisexualidad en el discurso de la secretaria, del personaje de la secretaria que se queda con la poetisa por miedo. En este relato de espejos y de identificaciones, las exalumnas oscilan, ya no quieren enfrentarse con este espejo.

Si encontrarse con la mirada de la Medusa es encontrarse con una mirada que petrifica, que esencializa, que fija una imagen de mujer, Matilde ya no quiere mirar para no quemar por contacto "no trate de abrirme los ojos porque desde hace muchos años yo no quiero mirar para no herir" (1971: 109). Por esa razón, no pretende seguir reproduciendo un discurso masculino. En la voz y en las reflexiones de las jóvenes generaciones, en los personajes de Cecilia Rojas y su amiga Susana se desarrolla una mirada crítica que les permite distanciarse de los modelos. En este relato de ficción, se pone en escena la constitución de una subjetividad, de una "identidad" en la cual las mujeres se construyen por efecto del lenguaje y la representación. En este sentido, consideramos que con la factura de este texto, con su discurso, Rosario Castellanos parece adelantarse a posiciones feministas más actuales en las que se considera que las mujeres se construyen a partir de los efectos del lenguaje y la representación (De Lauretis, 1984). ${ }^{8}$

\section{A modo de conclusión}

En este artículo hemos presentado un enfoque intermedial para mostrar cómo Rosario Castellanos usa el mito de la Medusa al reflexionar sobre la condición femenina, la autorrepresentación y la problemática del espejo a partir de la metáfora de la fotografía. Hemos mostrado que mediante la ficción se visibiliza el modo en que las mujeres que escriben han sido fijadas en la cultura y, a la vez, cómo por medio de figuras reflexivas se puede salir de los estereotipos para encontrar otras identificaciones. En este punto, sostenemos que la teoría de la fotografía y el concepto de "lo fotográfico" nos resulta productivo para entender las experimentaciones con el lenguaje y la representación que se

\footnotetext{
${ }^{8}$ Para Teresa de Lauretis: "las mujeres se construyen a partir de los efectos del lenguaje y la representación. Al igual que el espectador, punto final de la serie de imágenes fílmicas en movimiento, queda apresado en las sucesivas posiciones del significado y es arrastrado con ellas, una mujer (o un hombre) no es una identidad indivisible, una entidad estable de conciencia, sino el término de una serie cambiante de posiciones ideológicas. Dicho de otra manera, el ser social se construye día a día como punto de articulación de las formaciones ideológicas, encuentro siempre provisional del sujeto y los códigos en la intersección histórica (y, por ello, en continuo cambio) de las formaciones históricas y su historia personal" (De Lauretis, 1984: 29).
} 
exhibe en este texto y, por lo tanto, para pensar en cómo se imbrican las relaciones entre la literatura y la fotografía.

Al mismo tiempo, sostenemos que a partir de revisar cómo se representa la problemática del espejo, nos podemos acercar a las concepciones del feminismo de Castellanos que pareciera adelantarse a teorizaciones más actuales. Si atravesar el espejo es dejar la máscara y es encontrarse con un nuevo rostro, en esa imagen que aún no es imagen, como Matilde Casanova, en esa dislocación se encuentre un rostro nuevo abierto a las múltiples identificaciones del sujeto. Incluso, arriesgamos que el cuento "Álbum de familia" se cierra con la posibilidad de dos jóvenes estudiantes de salir del binarismo sexuado, de construir otros discursos, de escribir otros relatos, de usar otros lenguajes.

\section{Bibliografía}

Bustamante Bermúdez, Gerardo (2007), "Rasgos autobiográficos en Rito de iniciación de Rosario Castellanos", en Literatura Mexicana, vol. XVIII, n. ${ }^{\circ}$ 1, pp. 89-105. Consultado en <https://www.redalyc.org/pdf/3582/358242106004.pdf> (20/12/2020).

Castellanos, Rosario (1971), Álbum de familia. México, Joaquín Mortiz.

Castellanos, Rosario (1973), Mujer que sabe latín. México, FCE.

Castellanos, Rosario (2004), Rito de iniciación. México, Alfaguara.

CAStro RicAlde, Maricruz (2010), "Mujer que sabe latín: Rosario Castellanos y el ensayo”, en Pol Popovic Karic/Fidel Chávez Pérez (coord.), Rosario Castellanos. Perspectivas críticas. Ciudad de México, Tecnológico de Monterrey.

Cixous, Hélène (2001), La risa de la medusa. Ensayos sobe la escritura. Moix, Ana María (trad.). Barcelona, Anthropos.

CIXOus, Helene (2006), La llegada a la escritura. Agoff, Irene (trad.). Buenos Aires, Amorrortu.

DE LA CruZ, Sor Juana (2004), Obras completas. Lírica personal. Tomo 1. Ciudad de México, Fondo de Cultura Económica.

De Lauretis, Teresa (1996), (“La tecnología del género”, Bach, Ana María y Margarita Roulet (trads.). en Revista Mora, n. $^{\circ}$ 2, pp.6-34. Consultado <http://repositorio.filo.uba.ar/jspui/bitstream/filodigital/11003/1/uba_ffyl_r_mora_2.pdf > (20/12/2020).

DuboIs, Philippe (1986), El acto fotográfico. De la Representación a la Recepción. Baravalle, Graziella (trad.). Barcelona, Paidós.

Glantz, Margo (1994), "Las hijas de la malinche", en Esguince de cintura. Ciudad de México, Lecturas mexicanas, pp.178-197.

KRAuss, Rosalind (2002), Lo fotográfico. Por una teoría de los desplazamientos. Zelich, Cristina (trad.). Barcelona, Gustavo Gili.

Marcos Lantero, Inés (2008), "Hélène Cixous. La risa de la medusa", Lletra de Dona in Centre Dona $i$ Literatura. Barcelona, Centre Dona i Literatura / Universitat de Barcelona. Consultado en <http://www.ub.edu/cdona/lletradedona/la-risa-la-medusa-ensayos-sobre-la-escritura> $(15 / 12 / 2020)$. 
MATEu Serra, Rosa (1996), “Álbum de familia: la máscara como instrumento de desmitificación”, en Scriptura, n. ${ }^{\circ}$ 12, pp. 77-89. Consultado en <https://repositori.udl.cat/handle/10459.1/47990> $(15 / 12 / 2020)$.

PAECH, Jochen (1998), “Intermedialität. Mediales Differenzial und Transformative Figuren”, en Helbig Jörg (ed.), Intermedialität. Múnich, Fink, pp. 14-30.

Pollock, Griselda (2013), Visión y diferencia. Feminismo, feminidad e historias del arte. Buenos Aires, Fiordo.

RAJEWSKY, Irina (2002), Intermedialität. Tubinga, A. Franke.

SEFCOVICH, Sara (1987), México: país de ideas, país de novelas (una sociología de la literatura mexicana). Ciudad de México, Grijalbo.

VAlenzuela, Luisa (2010), "Rosario Castellanos. Mujer de la palabra, arco entre dos mundos", en Pol Popovic, Karic y Fidel Chávez Pérez (coords.), Rosario Castellanos perspectivas críticas. Perspectivas críticas. Ciudad de México, Tecnológico de Monterrey, pp. 361-379.

VERnANT, Jean-Pierre (1985), La muerte en los ojos. Figuras del Otro en la antigua Grecia. Zadunaisky, Daniel (trad.). París, Hachette.

Vernant, Jean-Pierre (1999), En el ojo del espejo. Pons, Horacio (trad.). Buenos Aires, Fondo de Cultura Económica.

WOLF, Werner (2011), “(Inter) mediality and the Study of Literatura", en CLCWeb: Comparative Literature and Culture, vol. 13, n. ${ }^{\circ} 3$. 